It should be noted that cortisol given at birth without the antigen had no subsequent effect on the ability of the animal to degrade the antigen (Group VI). It should also be noted that BSA given alone (Group VII) did not affect the survival of mice up to 6 weeks of age. However, within 2 weeks after injection both the large dose (Group V) and the small dose (Group I) of cortisol had decreased the survival rate of injected mice. It is suggested that the small dose was sufficient to cause a feedback inhibition of normal adrenal cortical hormone output. The mediumsize dose (Group III) supplied a sufficient replacement dose for normal output. The large dose (Group V) was of itself toxic when given with the BSA. Since serum albumins readily bind cortisol, the effect of the hormone in Group $\mathrm{V}$ animals was probably prolonged as compared with that in Group VI animals although they received the same dose.

The primary immune response to BSA measured at 6 weeks of age is significantly and progressively reduced by increasing doses of cortisol given at birth with the antigen. Concomitantly all doses of cortisol afforded a degree of protection from anaphylaxis at the challenge; the average score in the control group (Group VII) was 2.5 while the maximum average in all the other groups was $1 \cdot 6$.

The results presented in Table 1 are consistent with the original hypothesis, that is, that increasing doses of cortisol would increase the uptake of antigen by the immunologically competent cells and later reduce the immune response since it has previously been demonstrated that increasing doses of BSA given during the perinatal period do reduce the respons $\theta^{5}$. It is interesting but not explained that the secondary response, measured at the rechallenge, is unaffected by the treatment with cortisol.

It is also possible that the cortisol treatment does not merely affect the induction of the immune response during the perinatal period but that it permanently alters the hypophyseal control of adrenal corticoid output producing a prolonged effect on the immune response either through destruction of lymphoid tissue ${ }^{B}$ or through direct inhibition of antibody synthesis?

Cortisol will produce an involution of lymphoid tissue, especially of the thymus, when administered to adult adrenalectomized mice. If the primary immune response were merely a reflexion of the amount of functioning lymphoid tissue remaining after destruction by cortisol treatment at birth, these results might also be explained on this basis.

This work was supported by a U.S. Public Health Service grant.

Garr L. Sorem Geronimo Terres

Department of Physiology, Stanford University, California.

1 Michaelides, M. C. Fed. Proc 16 426 (1957). Michaelides, M. C., and Coons, A. H., J. Exp. Med., 11\%, 1035 (1963).

${ }^{2}$ Ambrose, C. T., Fed. Proc., 22, 266 (1963); Nat. Cancer Inst. Monogr. No. 11, 117 (1963); J. Exp. Med.,119, 1027 (1964).

' Halliday, W. J., and Garvey, J. S., Nature, 202, 712 (1964); J. Immunol., 93. 757 (1964)

- Terres, G., and Hughes, W. L., J. Immunol., 83, 459 (1959).

'Sorem, G. L., and Terres, G., J. Immunol, 90, 217 (1963).

- Santisteban, G. A., and Dougherty, T. F., Endocrinology, 54, 130 (1954).

'Shewell, J., and Long, D. A., J. Hyg., 54, 542 (1956).

\section{P, Blood Group Substance in Lumbricus terrestris (Earthworm) and Ascaris suum}

Cameron and Staveley ${ }^{1}$ found that the echinococcus oyst fluid contains $P$ blood group substance if thore are scolices present in the cysts. When the echinococcus cyst fluid is used as an antigen, excellent anti- $P_{1}$ sera are produced in goats ${ }^{2}$. In rabbits the production of $P_{1}$ antibodies can also be stimulated, but not by application of the eyst fluid alone ${ }^{3}$. We have explored another source of ant:gen, Lumbricus terrestris ${ }^{4}$. Sodium chloride extracts, both cooked and uncooked, contain a fairly large amount of $P_{1}$ substance together with $H$ substance and $B$ blood group substance. Some of the extracts inhibited also anti- $A$, but never anti- $M$, anti- $N$, or anti- $D$. The long. lasting immunity of man against Ascaris gave rise to the idea that the $P_{1}$ cold antibodies which are 'genuinely' present in the sera of $P_{2}$ group people could have developed following antigenic stimulation by Ascaris lumbricoides or other nemathelminthes. We therefore studied sodium chloride extracts from Ascaris sum and observed a high content of substance inhibiting anti- $P_{1}$ sera as well as $A$ and $H$ substances. By means of sodium chloride extracts from Lumbricus, $P_{2}$ erythrocytes pretreated with tannin can be transformed. into $P_{1}$ erythrocytes. The extract can be cooked and we have been using it for the immunization of goats. The detailed quantitative relations will be referred to elsewhere.

\section{O. Prokop}

D. SCHLESINGER

Institute for Forensic Medicine, Humboldt University, Berlin.

${ }^{2}$ Cameron, G. I., and Staveley, J. M., Nature, 179, 147 (1957), Kerde, Ch., et al., Ztschr. f. Immun. Forsch., 119, 216 (1960).

3 Prokop, O., and Oesterle, P., Blut, 4, 157 (1958).

- Prokop, O., and Schlesinger, D., Acta Biol. German., 15, 1 (1965).

\section{PATHOLOGY}

\section{Rapid Ascites Tumour Production}

KIESELGUHR has been found to promote Ehrlich's ascites tumour growth ${ }^{1}$. The usefulness of this procedure has been brought to my notice by various workers who require large yields of tumour or ascites fluid from mice, and this has prompted a more detailed report on the kieselguhr effect.

$B A L B / c$ female mice of 12-14 weeks of age, weighing between 20 and $25 \mathrm{~g}$, were used. Several experiments were carried out and the results (confirming each other) have been pooled. A sterile suspension of kieselguhr was prepared in saline. This sediments rapidly and the mixture needs constant shaking during injection procedures even within the syringe. Mice were injected intra. peritoneally with about $6 \mathrm{mg}$ of kieselguhr in sterile saline using a fairly large bore needle (s.w.G. 17).

A fow hours later $10 \times 10^{6}$ viable Ehrlich's ascites tumour cells were injected intraperitoneally. Animals were weighed daily and a small number killed each day to assay fluid and tumour cells. Control animals were given saline injections instead of kieselguhr and then also $10 \times 10^{6}$ cells intraperitoneally. Further controls were given kieselguhr or saline only. The results are shown in Figs. 1-3.

Kieselguhr-treated animals bearing tumours all increased in weight more rapidly than controls (see Fig. 1).

It is seen from Fig. 2 that kieselguhr increases considerably the volume of ascitic fluid produced. Animals receiving kieselguhr but no tumour developed a small amount of clear exudate (up to $0.5 \mathrm{ml}$.) within the peritoneal cavity for several days after injection. A larger tumour cell population was found in treated animals bearing tumours than in controls (see Fig. 3), though not in proportion to the increase in ascitic fluid. This is due to the density of tumour cells in the ascitic fluid of kieselguhr-treated mice being less than in controls. The packed cell volume of tumour cells (as determined by microhaemocrit centrifugation) at comparable days after tumour inoculation for the two groups varied widely. For example, 6 days after injection the packed cell volume of ascitic fluid from kieselguhr-treated animals ranged from 20 per cent to 32 per cent (average 25 per cent), while the saline-treated controls ranged from 28 per cent to 42 per cent (average 33 per cent). 